\title{
EPISTEMOLOGIA EM SALA DE AULA: A NATUREZA DA CIÊNCIA E DA ATIVIDADE CIENTÍFICA NA PRÁTICA PROFISSIONAL DE PROFESSORES DE CIÊNCIAS
}

\author{
Epistemology in classrooms: \\ science and scientific activity's nature \\ in science teachers' professional practice
}

\author{
Maura Ventura Chinelli ${ }^{1}$ \\ Marcus Vinícius da Silva Ferreira ${ }^{2}$ \\ Luiz Edmundo Vargas de Aguiar ${ }^{3}$
}

\begin{abstract}
Resumo: Este artigo apresenta resultados de uma pesquisa que procurou identificar as diferentes concepções epistemológicas que se encontram incorporadas à prática profissional de professores de ciências. Como resultado, tem-se que existem, em diferentes proporções, convivendo nas escolas, concepções epistemológicas distintas, sugerindo a ocorrência de uma crise paradigmática que pode justificar dificuldades para o aprendizado das ciências. A pesquisa reafirma a necessidade de se incluírem estudos da epistemologia e da história das ciências nos cursos de formação de professores e acrescenta a necessidade de se incluírem estudos sociológicos sobre o currículo, tendo em vista o caráter social da construção do conhecimento no paradigma que busca se impor.

Palavras-chave: Concepções dos professores. Ensino de ciências. Epistemologia. Natureza da ciência.

Abstract: This paper shows outcomes of a research that aimed to identify the different epistemological conceptions incorporated into the professional practice of science teachers. As a result, there are, in different proportions, living in the schools, distinct epistemological conceptions, suggesting the occurrence of a paradigmatic crisis, justifying the difficulties in learning science. This research reaffirms the necessity of including studies of the epistemology and the history of science in initial teachers training courses, and adds the necessity to include also sociological studies, especially those about the curriculum, bearing in mind the social character of the construction of the knowledge in the paradigm that one wants to encourage.
\end{abstract}

Keywords: Teachers' conceptions. Science teaching. Epistemology. Nature of science.

\footnotetext{
${ }^{1}$ Bacharel e Licenciada em Química. Doutora em Ciências. Docente, Departamento Sociedade, Educação e Conhecimento, Faculdade de Educação, Universidade Federal Fluminense. Niterói, RJ, Brasil.

$<$ maurachi.uff@gmail.com>

${ }^{2}$ Licenciando em Química. Instituto Federal de Educação, Ciência e Tecnologia do Rio de Janeiro, RJ, Brasil. <vinixp@oi.com.br>

${ }^{3}$ Bacharel e Licenciado em Química. Doutor em Ciências. Docente, Programa de Pós-Graduação em Ensino de Biociências e Saúde, Instituto Oswaldo Cruz, Fundação Oswaldo Cruz; Instituto Federal de Educação, Ciência e Tecnologia do Rio de Janeiro, RJ, Brasil.<edmundoaguiar@gmail.com>
}

${ }^{1}$ Av. Visconde do Rio Branco, $\mathrm{s} / \mathrm{n}^{\circ}$

Campus Gragoatá, Bloco D

São Domingos, Niterói - Rio de Janeiro, RJ

$24.210-200$ 


\section{Introdução}

Temos testemunhado um amplo debate em torno da necessidade de se modificarem os currículos escolares, no que diz respeito ao ensino das ciências. Há sinais incontestáveis da inadequação das práticas pedagógicas tradicionais, o que resulta no fracasso de muitos estudantes e no crescente desinteresse pela aprendizagem das ciências.

Estudos realizados em 2002 pela $\mathrm{OCDE}^{4}$ atribuem o desinteresse dos jovens pelas carreiras que tratam das ciências e das tecnologias a uma questão de sentido: os estudantes rejeitam a proposta da escola de apresentar-lhes o mundo sob a interpretação de uma ciência fria e metódica, distante dos seus interesses. Desejam que o ensino deixe clara a importância dos conhecimentos científicos e tecnológicos para ajudá-los a compreender melhor o mundo em que vivem (OCDE, 2002).

A constatação é particularmente significativa quando colocada frente às mudanças mais recentes na forma de conceber a atividade científica. Essas mudanças reconhecem, no contexto cultural, a coerência intelectual que sustenta a escolha dos métodos e a interpretação dos resultados das investigações científicas, ao mesmo tempo em que admitem o impacto do desenvolvimento científico e tecnológico sobre a sociedade (PRIGOGINE e STENGERS, 1991). Isso exige a formação de uma consciência moral - seja do cientista, seja do cidadão visando ao controle ético e político da atividade científica (MORIN, 2005, 2003), e evidencia uma tendência para superar-se a tradicional distinção entre as ciências naturais e as ciências sociais (SANTOS, 2004a, 2004b). Os jovens pesquisados pela OCDE parecem estar sintonizados com o novo paradigma científico, o que traria certo desconforto em relação à visão tradicional das ciências, ainda dominante nas escolas.

De fato, pesquisas sobre o ensino de ciências têm demonstrado que visões já superadas sobre a natureza da ciência e do trabalho científico têm sido um dos principais obstáculos para a renovação do ensino de ciências (GALLEGO TORRES e GALLEGO BADILLO, 2007; PRAIA, GIL-PÉREZ e VILCHES, 2007; CACHAPUZ et al., 2005; CACHAPUZ, PRAIA e JORGE, 2004; FOUREZ, 2003; PRAIA, CACHAPUZ e GIL-PÉREZ, 2002; HARRES, 1999; CARVALHO e GIL-PÉREZ, 1995). É consenso, entre esses autores, que da concepção epistemológica deriva a concepção de ciência que é ensinada, e que o conhecimento da epistemologia torna os professores mais capazes de compreenderem a ciência que ensinam, ajudando-os na preparação e na organização de suas aulas, o que os leva a apontarem a importância da inclusão de disciplinas sobre história e epistemologia nos currículos da formação inicial e continuada dos professores.

Mas a formação docente não se dá apenas nas atividades acadêmicas. Diferentes estudos comprovam que a prática profissional dos professores é influenciada por sua trajetória pessoal (CHINELLI e AGUIAR, 2008a; CHINELLI, 2001; TARDIF e RAYMOND, 2000; CARVALHO e GIL-PÉREZ, 1995; THERRIEN, 1993; NÓVOA, 1992, entre outros), o que

\footnotetext{
${ }^{4}$ Organização para Cooperação e Desenvolvimento Econômico. Organização internacional e intergovernamental que agrupa os países mais industrializados da economia do mercado a fim de trocar informações e definir políticas com o objetivo de realizar a maior expansão possível da economia, do emprego e da qualidade de vida dos países membros.
} 
Epistemologia em sala de aula: a natureza ...

significa que aprendizagens não formais também são responsáveis pela formação de conceitos sobre a ciência, os cientistas, a atividade científica e o significado de ser professor de ciência.

Com base neste princípio, a investigação em didática das ciências tem se voltado, em alguma medida, para o estudo das concepções dos professores sobre a natureza da ciência e da atividade científica. O interesse neste tema, de acordo com Fernandes et al. (2002), parte da convicção de que as pré-concepções, ideias e comportamentos que os professores trazem sobre as ciências e sobre o ensino podem entrar em conflito com o que a pesquisa em didática das ciências tem mostrado.

Neste trabalho, estudamos a presença de diferentes concepções sobre a natureza da ciência e da atividade científica nas práticas pedagógicas de professores de ciências, com o objetivo de identificar em que proporção o estágio atual de desenvolvimento da ciência tem sido incorporado ao ensino de ciências nas escolas.

Ele faz parte de um estudo mais amplo em que, partindo do pressuposto de que as experiências sociais e temporais dos professores também se constituem em importantes contribuições para a sua formação, irá subsidiar a identificação de oportunidades de adequação epistemológica e didática de professores de ciências em experiências não acadêmicas que possam enriquecer o currículo da formação docente.

\section{Metodologia}

Trata-se de uma pesquisa descritiva de corte transversal, para a qual empregamos um questionário fechado (RICHARDSON, 2007) contendo dezesseis afirmativas que se propuseram a descrever, com menção às práticas correntes nas escolas, aspectos que caracterizam o pensamento clássico ou o pensamento complexo do estágio atual do desenvolvimento da ciência, de modo a possibilitar que fosse identificada a afinidade dos professores pesquisados com as diferentes concepções epistemológicas que se manifestam no ensino de ciências.

As afirmativas correspondem a oposições apontadas por Fourez (2003) entre alguns temas que estruturam e justificam muitas práticas adotadas nas escolas, sugerindo a ocorrência de uma crise paradigmática que pode justificar dificuldades para o aprendizado de ciências. Essas oposições foram interpretadas por Chinelli e Aguiar (2008b) em relação ao paradigma moderno, clássico, e ao paradigma pós-moderno, que vem se impondo, sendo apropriadas, neste trabalho, como a base para o questionário dirigido aos professores.

Inspirados em pesquisa realizada por Moreira, Massoni e Ostermann (2007), propusemos as afirmativas admitindo, para cada uma, quatro tipos de respostas (concordo plenamente; concordo parcialmente; discordo; estou indeciso), e as distribuímos aleatoriamente no questionário para evitar a indução das respostas, como poderia ocorrer se estivessem organizadas por pares de opostos.

Havia a intenção de alcançar um grande número de professores, em todo o Brasil, de modo que o movimento inicial foi divulgar a pesquisa em comunidades de professores das disciplinas científicas, organizadas na Internet, mas o retorno foi muito pequeno. O questionário, disponibilizado em um site criado exclusivamente para esse fim, permitia a escolha das opões on-line e o seu envio para uma conta de e-mail também exclusiva, sem que os respondentes pudessem ser identificados. 
A estratégia mostrou-se muito interessante, mas não suficiente. Por esta via, pretendíamos atingir cerca de 14 mil professores - número total de membros das comunidades escolhidas - com retorno de, pelo menos, $1 \%$, mas obtivemos apenas 16 respostas em um mês. Não podemos discutir as causas para que tenha ocorrido desta forma. Partimos então para o contato direto em escolas ou utilizando correio eletrônico, optando por usar uma amostra aleatória simples de cinquenta professores - de biologia, física, matemática e química - que lecionam no Estado do Rio de Janeiro.

Eles estão caracterizados como: 17 professores de biologia, oito professores de física, nove professores de matemática (dois deles, engenheiros) e 16 professores de química (três engenheiros químicos e um graduado em farmácia).

Quanto ao tempo de magistério, estão distribuídos da seguinte forma: lecionando há mais de 24 anos, quatro professores; entre 16 e 23 anos de magistério, seis professores; lecionando entre oito e 15 anos, 11 professores; com menos de sete anos de magistério, 24 professores. Responderam ao questionário, por já estarem exercendo funções de magistério, cinco licenciandos.

Neste grupo há 21 professores com curso de especialização (pós-graduação, latosensu), quatro mestres e cinco doutores, muitos deles lecionando em mais de um nível de ensino: 21 atuam no Ensino Fundamental; 36, no Ensino Médio; e 11, no Ensino Superior.

Para a interpretação dos resultados, foram observadas as frequências de respostas em cada alternativa, comparadas nos pares que procuram retratar as oposições observadas nas práticas escolares, de acordo com a perspectiva clássica e a perspectiva do atual estágio de desenvolvimento das ciências.

\section{A natureza da ciência e da atividade científica na prática profissional de professores}

Logo no primeiro olhar, nos deparamos com uma dificuldade: a maior parte dos professores diz concordar, total ou parcialmente, com todas as afirmações. Procurando encontrar um caminho para a análise, passamos a observar a frequência das respostas do tipo "Concordo plenamente!" e "Concordo...parcialmente." em conjunto com a frequência das respostas do tipo "Discordo.", na afirmativa que traz o pensamento oposto. Observamos ainda a soma dos professores que diz concordar plenamente com ambas as afirmativas - em sete dos oito pares formados esta soma excede o número de informantes, significando que alguns desses professores, de fato, não percebem haver divergências entre as afirmativas que se opõem.

Estes dados estão sistematizados e discutidos a seguir. Em todos os pares, as afirmações que procuram expressar a perspectiva atual, pós-moderna, precedem as afirmações relacionadas com a perspectiva clássica, moderna.

$1^{a}$ oposição: Promover a alfabetização científica e tecnológica que se destina à familiarização com conceitos abrangentes, de modo a dar instrumentos para as pessoas participarem dos debates democráticos que exigem conhecimento e senso crítico acerca das ciências e das tecnologias x Formar nos conhecimentos específicos de um determinado campo; ensinar a decodificar a natureza e a prever o comportamento dos fenômenos naturais (Tabela 1, Gráfico 1). 
Epistemologia em sala de aula: a natureza ...

Tabela 1. Oposição entre a alfabetização científica e tecnológica e a formação nas especificidades das ciências.

\begin{tabular}{|c|c|c|c|c|c|}
\hline & \multirow[b]{2}{*}{ Afirmativas } & \multicolumn{4}{|c|}{ Frequência } \\
\hline & & Concordo & Concordo... & Discordo & Estou \\
\hline 10 & $\begin{array}{l}\text { Os currículos que privilegiam conhecimentos } \\
\text { profundos e abstratos afastam os estudantes } \\
\text { das ciências. É preciso familiarizá-los com } \\
\text { conceitos gerais, abrangentes, para despertar o } \\
\text { interesse pela ciência e dar instrumentos para a } \\
\text { tomada de decisões. }\end{array}$ & 25 & 22 & 2 & 1 \\
\hline \multirow[t]{2}{*}{7} & $\begin{array}{l}\text { Todos deveriam aprender a ciência dos } \\
\text { cientistas, mesmo que pareça abstrata e não } \\
\text { faça sentido para alguns estudantes. Os alunos } \\
\text { que pretendem seguir carreiras científicas não } \\
\text { podem ser prejudicados pelo desinteresse ou } \\
\text { incapacidade de outros. }\end{array}$ & 11 & 16 & 18 & 5 \\
\hline & $\begin{array}{l}\text { Responderam, concomitantemente, a ambas as } \\
\text { afirmativas }\end{array}$ & - & - & - & - \\
\hline
\end{tabular}

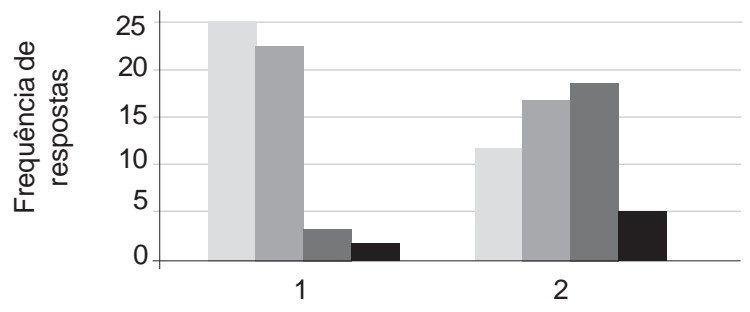

Concordo plenamente!

Concordo... parcialmente

Discordo

Estou indeciso(a)...

1. Paradigma emergente, pós-moderno

2. Paradigma clássimo, moderno

Gráfico 1. Alfabetização científica e tecnológica x Formação nas especificidades das ciências.

A maior parte dos professores concorda que seja necessário familiarizar os alunos com conceitos gerais que despertem o interesse e sirvam de instrumentos para a tomada de decisões, dividindo-se entre concordar plenamente (50\%) e concordar parcialmente (44\%) com a primeira afirmativa, afinada com os princípios atuais de socialização do conhecimento e de crítica ao abandono dos cidadãos à ignorância dos seus próprios problemas (SANTOS, 2004a, 2004b; MORIN, 2003; PRIGOGINE e STENGERS, 1991). 


\section{Chinelli, M. V.; Ferreira, M. V. S.; Aguiar, L. E. V.}

Já as respostas à segunda afirmativa mostram os professores divididos: um número significativo $(22 \%)$ pensa ser necessário conhecer a ciência "dos cientistas", mesmo que pareça abstrata, sendo que $32 \%$ concordam apenas em parte com esta afirmação. O número de professores que diz discordar desta afirmativa (36\%) chama a atenção e há 10\% de indecisos.

Estes resultados indicam a inclinação dos professores analisados pela perspectiva atual, orientada pelo paradigma pós-moderno, mas indicam também muita incerteza em relação ao ensino informativo da escola tradicional, de perspectiva clássica, que propõe o aprofundamento nos vários campos do conhecimento. São resultados que expõem a coexistência de duas orientações diferentes para os objetivos curriculares, evidenciando a crise do ensino de ciências nas escolas.

$2^{\mathbf{a}}$ oposição: Formar para a solução de problemas concretos e inesperados x Formar para a assimilação do conhecimento acumulado (Tabela 2, Gráfico 2).

Tabela 2. Oposição entre saber usar o conhecimento e saber acumular conhecimento.

\begin{tabular}{|c|c|c|c|c|c|}
\hline & \multirow[b]{2}{*}{ Afirmativas } & \multicolumn{4}{|c|}{ Frequência } \\
\hline & & $\begin{array}{c}\text { Concordo } \\
\text { plenamente! }\end{array}$ & $\begin{array}{l}\text { Concordo... } \\
\text { parcialmente }\end{array}$ & Discordo & $\begin{array}{c}\text { Estou } \\
\text { indeciso (a) }\end{array}$ \\
\hline 4 & $\begin{array}{l}\text { O professor deve desenvolver nos alunos a } \\
\text { capacidade de buscarem informações que } \\
\text { possam ser relevantes em um dado momento; } \\
\text { de usarem o conhecimento para analisar } \\
\text { criticamente situações de vida, e de intervirem } \\
\text { com base nesses conhecimentos. }\end{array}$ & 46 & 3 & 1 & 0 \\
\hline \multirow[t]{2}{*}{1} & $\begin{array}{l}\text { O professor é o responsável pela transmissão } \\
\text { do conhecimento acumulado pela humanidade. } \\
\text { Em ciências, há muitas descobertas importantes } \\
\text { que os alunos precisam conhecer. Quem não } \\
\text { sabe as principais leis científicas não aprendeu } \\
\text { ciências. }\end{array}$ & 14 & 25 & 11 & 0 \\
\hline & $\begin{array}{l}\text { Responderam, concomitantemente, a ambas as } \\
\text { afirmativas }\end{array}$ & 10 & - & - & - \\
\hline
\end{tabular}

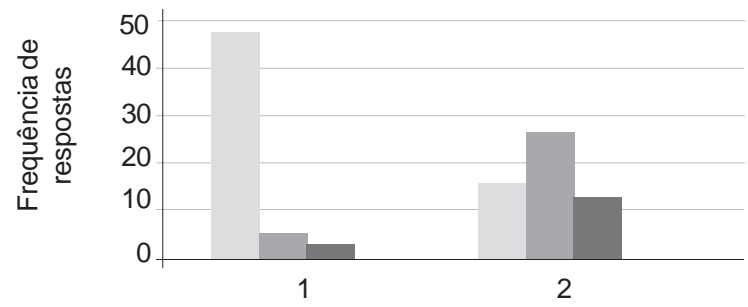

Concordo plenamente!

Concordo... parcialmente

- Discordo

Estou indeciso(a)...

1. Paradigma emergente, pós-moderno

2. Paradigma clássimo, moderno

Gráfico 2. Saber usar o conhecimento x Saber acumular conhecimento. 
Quase a totalidade dos professores pesquisados (92\%) considera importante que os alunos aprendam a buscar conhecimentos e que saibam usá-los na solução de problemas reais, cotidianos. Outros $6 \%$ concordam, ao menos em parte, com esta afirmativa e as divergências praticamente inexistem. Este resultado indica uma forte afinidade dos professores pesquisados com o paradigma atual, que propõe, para a educação formal, o desenvolvimento de métodos e atitudes que permitam a transferência de modelos e a intervenção em contextos relacionados à vida prática.

No entanto, $28 \%$ dos pesquisados mostraram acreditar fortemente que o professor deve informar aos alunos as "principais" descobertas científicas - uma opção coerente com o princípio que diz haver, na natureza, verdades inquestionáveis que podem ser descobertas por meio do método científico. Isto resulta em que, neste item, $20 \%$ dos professores tenham concordado plenamente com ambas as afirmações, indicando a presença, nas práticas curriculares, de duas concepções epistemológicas distintas. Este é um indício de que não está claro, para os professores pesquisados, se devem ou não transmitir aos alunos os conhecimentos que constam dos currículos tradicionais, e se é ou não possível fazê-lo sem que excluam conhecimentos novos, alguns extremamente relevantes.

O índice de discordância à afirmativa clássica $(22 \%)$ demonstra que estes professores consideram pouco adequado tentar transmitir conhecimentos que são hoje muito volumosos e muito específicos, tornando-se mesmo abstratos, que podem vir a ser substituídos brevemente por novos conhecimentos, melhor aceitos pela comunidade científica.

Estes resultados confirmam a existência de um conflito entre paradigmas, na educação formal em ciências.

$3^{\mathbf{a}}$ oposição: Formar o indivíduo como membro de uma coletividade, sendo capaz de comunicar-se, de deliberar coletivamente e de integrar as contribuições dos especialistas ao debate de Questões de interesse coletivo x Formar o indivíduo para que demonstre capacidade para o acúmulo de conhecimentos, visando a favorecer o seu sucesso pessoal (Tabela 3, Gráfico 3).

Tabela 3. Oposição entre a capacitação científica da coletividade e a capacitação científica do indivíduo.

\begin{tabular}{|c|c|c|c|c|c|}
\hline & \multirow[b]{2}{*}{ Afirmativas } & \multicolumn{4}{|c|}{ Frequência } \\
\hline & & $\begin{array}{l}\text { Concordo } \\
\text { plenamente! }\end{array}$ & $\begin{array}{l}\text { Concordo... } \\
\text { parcialmente }\end{array}$ & Discordo & $\begin{array}{c}\text { Estou } \\
\text { indeciso (a) }\end{array}$ \\
\hline 6 & $\begin{array}{l}\text { Somos membros de uma coletividade à qual } \\
\text { interessa o desenvolvimento científico. Os } \\
\text { alunos devem aprender que o acesso ao } \\
\text { conhecimento científico é direito de todos e que, } \\
\text { muitas vezes, é preciso deliberar coletivamente } \\
\text { com base na ciência. }\end{array}$ & 34 & 11 & 3 & 2 \\
\hline \multirow[t]{2}{*}{9} & $\begin{array}{l}\text { O professor é responsável pela formação do } \\
\text { indivíduo. Os conhecimentos que ele transmite } \\
\text { aos alunos, e que são adquiridos de maneiras } \\
\text { diferentes por cada um, é que serão usados no } \\
\text { enfrentamento de situações competitivas } \\
\text { naturais na vida. }\end{array}$ & 20 & 24 & 6 & 0 \\
\hline & $\begin{array}{l}\text { Responderam, concomitantemente, a ambas as } \\
\text { afirmativas }\end{array}$ & 4 & - & - & - \\
\hline
\end{tabular}




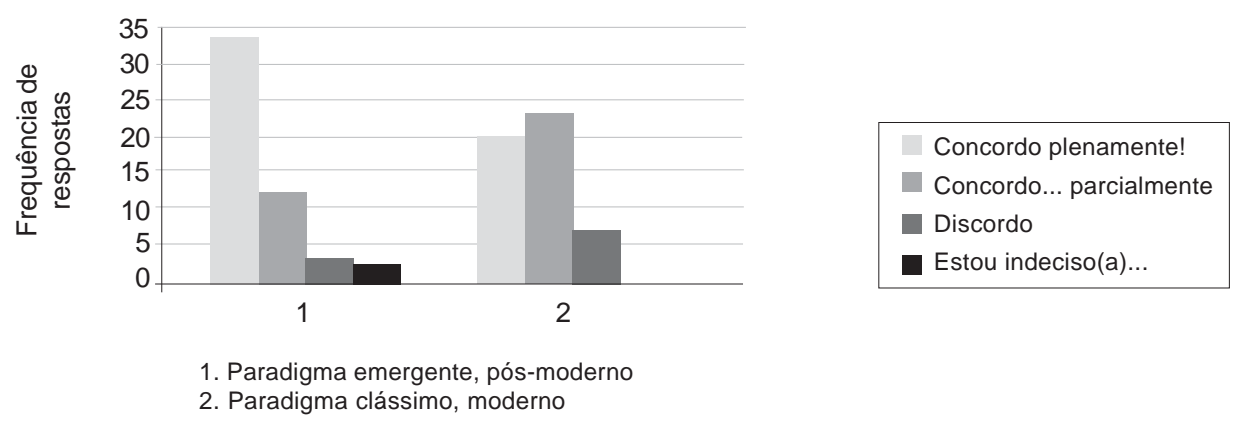

Gráfico 3. Capacitação científica da coletividade x Capacitação científica do indivíduo.

A maioria dos professores $(68 \%)$ concorda plenamente que o conhecimento científico interessa ao conjunto dos cidadãos e que estes deverão participar de decisões coletivas acerca do desenvolvimento da ciência e de suas aplicações. Os demais concordam apenas parcialmente com este conceito $(22 \%)$, havendo ainda aqueles que discordam $(6 \%)$ e os que estão indecisos (4\%).

Estes resultados nos preocupam, visto que informam haver, subjacente à prática profissional de alguns destes professores, uma ideologia que os leva a aceitarem que, a despeito de estarmos todos no mesmo mundo, profundamente influenciado pelo desenvolvimento científico e tecnológico, somente alguns possam ter acesso ao conhecimento, enquanto outros não; a acreditar que só uns poucos devam ser responsáveis pelas decisões acerca do uso das ciências e das tecnologias, mesmo que essas decisões venham a afetar indiscriminadamente todas as pessoas.

$\mathrm{Na}$ segunda afirmativa, a expressão "O professor é responsável pela formação do indivíduo" pode ter prejudicado a sua interpretação - dificilmente um professor iria se manifestar em contrário -, induzindo a que $40 \%$ dos professores tenham concordado plenamente com a afirmação. Os $48 \%$ que concordam parcialmente e os $12 \%$ que discordam desta afirmativa, no entanto, parecem indicar que percebam que o ensino massificado, distanciado das condições de cada aluno para aproveitar as oportunidades para aprender - que privilegia os mais competentes em detrimento dos demais -, não esteja de acordo com a prática docente guiada por padrões éticos.

De todo modo, fica caracterizada a indefinição que revela a crise: só alguns professores estão convencidos de que seja necessário capacitar todos os cidadãos para lidarem com as transformações trazidas pelo desenvolvimento científico e tecnológico, o que é uma das características mais marcantes do paradigma que busca se impor. Outros permanecem privilegiando a capacitação individual de seus alunos, naturalizando o sucesso de uns, considerados os melhores, e o fracasso de outros, que não demonstram ser suficientemente capazes para participar do selecionado universo das ciências. 
Epistemologia em sala de aula: a natureza ...

Há, ainda, um grupo (8\%), que concorda simultaneamente com as duas possibilidades, ou seja, que acredita na necessidade de capacitar os alunos para participarem coletivamente na tomada de decisões para as quais sejam necessários conhecimentos científicos e tecnológicos; e, também, que é preciso preparar os estudantes individualmente, para que sejam bemsucedidos em situações competitivas.

$4^{a}$ oposição: Ensino que se propõe à compreensão de situações reais, para o qual as disciplinas e suas interseções precisam ser utilizadas em conjunto de modo a esclarecer fenômenos que são complexos x Ensino voltado para a compreensão dos fenômenos naturais, que devem ser explicados a partir de regras simples, sendo necessário, antes, dividir e classificar, para só depois determinar as relações entre as partes (Tabela 4, Gráfico 4).

Tabela 4. Oposição entre procurar abordagens interdisciplinares e manter a distinção entre as disciplinas.

\begin{tabular}{|c|c|c|c|c|c|}
\hline & \multirow[b]{2}{*}{ Afirmativas } & \multicolumn{4}{|c|}{ Frequência } \\
\hline & & Concordo & Concordo... & Discordo & Estou \\
\hline 2 & $\begin{array}{l}\text { A organização do currículo em disciplinas é uma } \\
\text { boa organização, mas, como a natureza é } \\
\text { complexa, é preciso estudar temas de interesse } \\
\text { dos estudantes, usando várias disciplinas em } \\
\text { conjunto. }\end{array}$ & 36 & 13 & 1 & 0 \\
\hline \multirow[t]{2}{*}{15} & $\begin{array}{l}\text { A especialização do conhecimento é garantia } \\
\text { para uma aprendizagem mais profunda e mais } \\
\text { eficaz de uma determinada ciência, embora um } \\
\text { mesmo assunto possa ser abordado por } \\
\text { professores de várias disciplinas para que os } \\
\text { alunos o entendam melhor. }\end{array}$ & 36 & 11 & 2 & 1 \\
\hline & $\begin{array}{l}\text { Responderam, concomitantemente, a ambas as } \\
\text { afirmativas }\end{array}$ & 22 & - & - & - \\
\hline
\end{tabular}

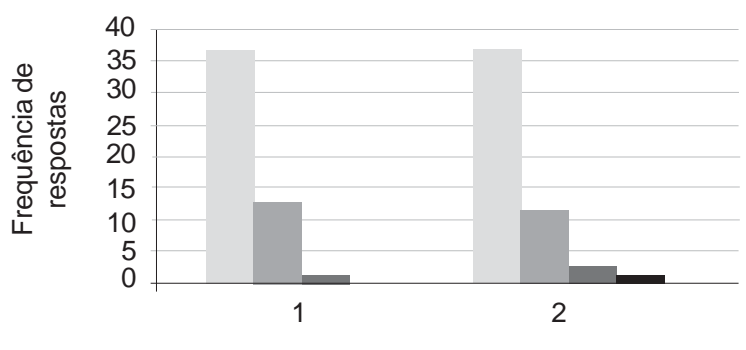

Concordo plenamente!
Concordo... parcialmente
Discordo
Estou indeciso(a)...

1. Paradigma emergente, pós-moderno

2. Paradigma clássimo, moderno

Gráfico 4. Procurar abordagens interdisciplinares x Manter a distinção entre as disciplinas. 
Neste item, os professores se manifestaram de modo muito semelhante em relação às duas afirmativas, implicando que $44 \%$ tenham respondido concordar plenamente com ambas.

Essa concordância maciça, ao contrário de indicar um conflito, parece dizer que a maior parte dos professores ( $72 \%$, em cada afirmativa) está convencida do discurso da interdisciplinaridade. Os $26 \%$ que disseram concordar apenas em parte, na primeira afirmativa, talvez estejam tão convencidos que desejem encontrar outra organização para a escola, sem disciplinas.

Os resultados sugerem que o conceito de interdisciplinaridade, para muitos desses professores, tenha o sentido dos olhares diferenciados, das interpretações variadas que os vários campos do conhecimento possam ter sobre um mesmo fenômeno, o que acaba por confirmar as barreiras disciplinares (MORIN, 2007, 2002), uma característica do paradigma moderno.

$\mathrm{Na}$ conceituação de Piaget (1979, p. 166), essas são práticas multidisciplinares, enquanto a interdisciplinaridade é uma abordagem em que "a cooperação entre várias disciplinas provoca intercâmbios e, conseqüentemente, enriquecimentos mútuos". A interdisciplinaridade, enquanto premissa do pensamento complexo que caracteriza o estágio atual do desenvolvimento da ciência é, portanto, uma maneira de construir conhecimento em que o conjunto das contribuições das várias disciplinas produz outra maneira de conhecer, em que forma-se um novo campo que está acima das barreiras disciplinares para poder compreender um determinado tema ou solucionar um problema (MORIN, 2007, 2002).

Mesmo que não evidenciem a existência de uma crise, estes resultados apontam a necessidade de esclarecer o tema entre os professores.

$5^{\mathbf{a}}$ oposição: Ensino baseado na experimentação, que se destina a observar resultados a fim de testar hipóteses e chegar a conclusões, organizado de modo a aproximar os estudantes dos métodos empregados no desenvolvimento das ciências x Ensino tradicional, teórico, em que a experimentação, quando há, está relacionada a protocolos rígidos de procedimentos, direcionada a confirmar a teoria exposta e a usar de precisão formal para confirmar hipóteses claras (Tabela 5, Gráfico 5):

Tabela 5. Oposição entre o ensino baseado na experimentação e o ensino baseado na teoria.

\begin{tabular}{|c|c|c|c|c|c|}
\hline & \multirow[b]{2}{*}{ Afirmativas } & \multicolumn{4}{|c|}{ Frequência } \\
\hline & & Concordo & Concordo... & Discordo & Estou \\
\hline 16 & $\begin{array}{l}\text { É preciso dar aos alunos a oportunidade de } \\
\text { realizarem experimentos na forma como fazem } \\
\text { os cientistas: construindo hipóteses que } \\
\text { possam ser testadas e formulando conclusões } \\
\text { diante dos resultados encontrados, apoiadas em } \\
\text { uma teoria aceita. }\end{array}$ & 29 & 21 & 0 & 0 \\
\hline \multirow[t]{2}{*}{3} & $\begin{array}{l}\text { Devemos ensinar a teoria formulada pelos } \\
\text { cientistas e fazer com que os alunos apliquem a } \\
\text { teoria na resolução de problemas. Levar os } \\
\text { alunos a realizarem experimentos é } \\
\text { interessante, pois os experimentos são úteis } \\
\text { para comprovar a teoria estudada. }\end{array}$ & 34 & 11 & 4 & 1 \\
\hline & $\begin{array}{l}\text { Responderam, concomitantemente, a ambas as } \\
\text { afirmativas }\end{array}$ & 13 & - & - & - \\
\hline
\end{tabular}




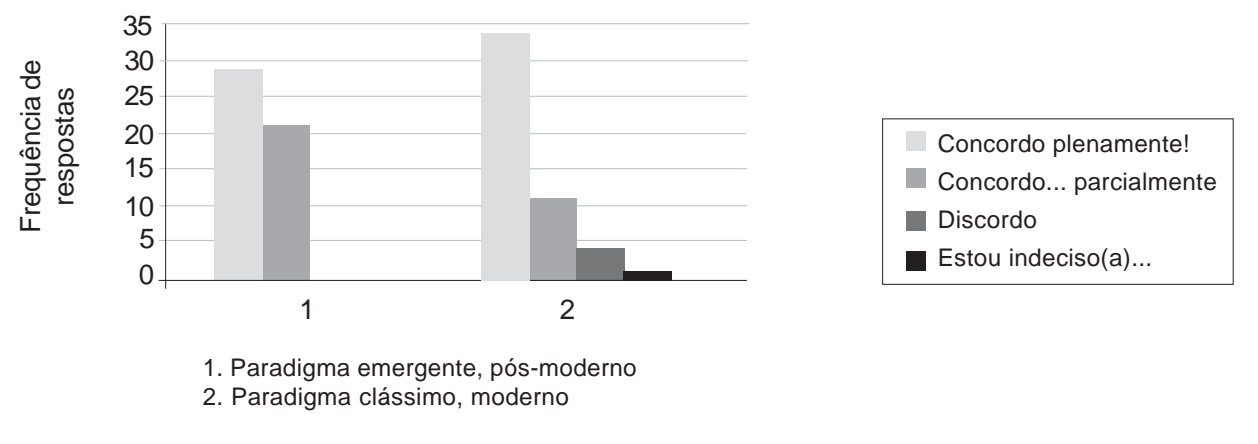

Gráfico 5. Ensino baseado na experimentação x Ensino baseado na teoria

Aqui parece que, para os professores pesquisados, ambas as possibilidades são boas: $26 \%$ dos consultados responderam concordar plenamente com as duas afirmações. Eles demonstram estar convencidos de que as atividades experimentais são um bom recurso pedagógico, não importando que possibilidades diferentes para aprender ciência uma e outra forma de experimentar permitam.

Ao responderem à Afirmativa 16, todos os professores demonstram, de alguma forma, perceber a experimentação como um eficiente recurso para a (re) construção de conceitos científicos: $58 \%$ deles concordam plenamente e $42 \%$ também concordam, embora com restrições.

Mas as respostas à Afirmativa 3 demonstram que a maior parte dos professores (68\%) vê a experimentação como uma forma de comprovar a teoria estudada, sendo que há ainda $22 \%$ que concordam, ao menos em parte, com esta afirmação.

Os $8 \%$ que discordam do uso didático da experimentação apenas para comprovar a teoria estudada são um sinal de que procedimentos apoiados nas teorias pedagógicas construtivistas começam a se impor nas práticas escolares. Mas não podemos afirmar que os professores consultados venham a optar por uma ou outra maneira de experimentar, na escola, mesmo que percebam que estão relacionadas a concepções diferentes sobre a natureza da ciência e da atividade científica.

$\mathbf{6}^{\mathbf{a}}$ oposição: Compreensão do progresso científico como intervenção humana sobre a própria natureza, o que requer analisar os efeitos dos produtos da ciência e da tecnologia sobre a sociedade e o ambiente x Compreensão da natureza como um campo independente do saber que elimina, ao estudá-la, tudo o que faz referência ao humano e às finalidades humanas (Tabela 6, Gráfico 6). 
Chinelli, M. V.; Ferreira, M. V. S.; Aguiar, L. E. V.

Tabela 6. Oposição entre ensinar as relações entre a ciência, a tecnologia, a sociedade e o ambiente e ensinar a ciência pura, precisa e lógica.

\begin{tabular}{|c|c|c|c|c|c|}
\hline & \multirow[b]{2}{*}{ Afirmativas } & \multicolumn{4}{|c|}{ Frequência } \\
\hline & & $\begin{array}{l}\text { Concordo } \\
\text { plenamente! }\end{array}$ & $\begin{array}{l}\text { Concordo... } \\
\text { parcialmente }\end{array}$ & Discordo & $\begin{array}{c}\text { Estou } \\
\text { indeciso }(a)\end{array}$ \\
\hline 16 & $\begin{array}{l}\text { O universo científico não tem razão de ser se não } \\
\text { se permite confrontar com o mundo no qual } \\
\text { vivemos. O ensino de ciências deve contribuir para } \\
\text { a compreensão dos conflitos da sociedade. }\end{array}$ & 35 & 15 & 0 & 0 \\
\hline \multirow[t]{2}{*}{3} & $\begin{array}{l}\text { Na escola, o ensino das ciências destina-se a } \\
\text { possibilitar que o aluno entre formalmente no } \\
\text { universo da ciência pura, precisa, lógica. A } \\
\text { verdadeira ciência é aquela que está isenta de } \\
\text { qualquer interesse. }\end{array}$ & 17 & 10 & 20 & 3 \\
\hline & $\begin{array}{l}\text { Responderam, concomitantemente, a ambas as } \\
\text { afirmativas }\end{array}$ & 2 & - & - & - \\
\hline
\end{tabular}

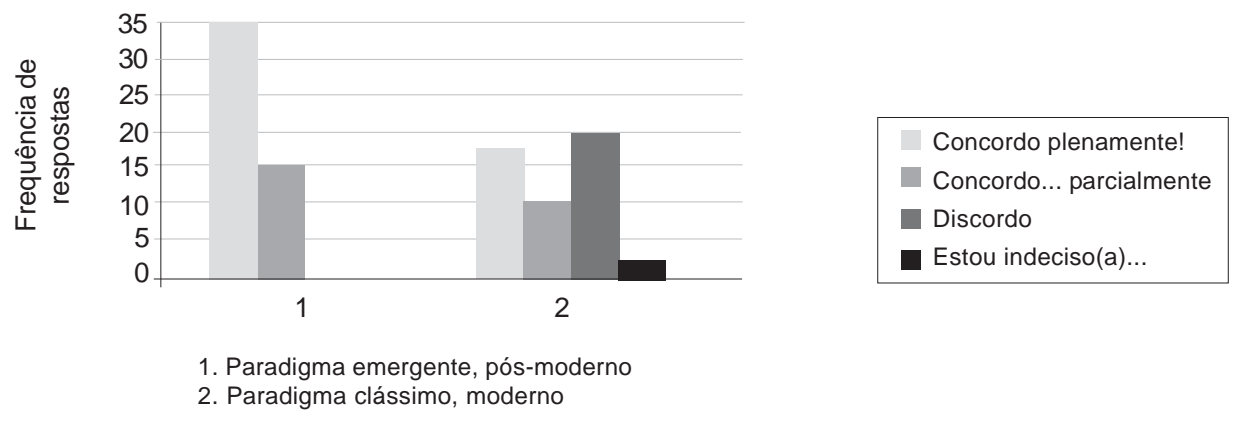

Gráfico 6. Ensinar as relações entre ciência, tecnologia, sociedade e ambiente x Ensinar a ciência pura, precisa e lógica.

Aqui, também, todos os professores concordam que o ensino de ciências deva contribuir para a compreensão dos conflitos da sociedade, o que pressupõe que seja necessário estudar ciências em suas relações com a sociedade, a tecnologia e o ambiente: $70 \%$ concordam plenamente e os demais, 30\%, também concordam, embora parcialmente. Estes resultados são reforçados pelos $40 \%$ que discordam da segunda afirmativa, que afirma ser, a verdadeira ciência, pura, precisa e lógica, isenta de qualquer interesse.

Esses resultados demonstram que grande parte dos professores admite que haja um papel social para as ciências. No entanto, $34 \%$ dos informantes ainda acreditam na ciência pura e desinteressada, o que, em muitas circunstâncias, expõe os estudantes a orientações epistemologicamente distintas, na aprendizagem das ciências. 
Epistemologia em sala de aula: a natureza ...

$7^{a}$ oposição: Educação em ciências visando a contribuir para a formação de uma consciência ética e política sobre a produção e o uso do conhecimento científico x Educação científica para a compreensão do universo formal das ciências, isenta de conflitos ideológicos (Tabela 7, Gráfico 7):

Tabela 7. Oposição entre ensinar a ciência em suas relações com a cultura e ensinar as ciências da natureza, independentes de todo contexto.

\begin{tabular}{|c|c|c|c|c|c|}
\hline & \multirow[b]{2}{*}{ Afirmativas } & \multicolumn{4}{|c|}{ Frequência } \\
\hline & & Concordo & Concordo... & Discordo & Estou \\
\hline 11 & $\begin{array}{l}\text { O conhecimento científico não está isolado de } \\
\text { suas condições de elaboração, sendo necessária } \\
\text { a formação de uma consciência moral - seja do } \\
\text { cientista, seja do cidadão - visando ao controle } \\
\text { ético e político da atividade científica. }\end{array}$ & 34 & 14 & 2 & 0 \\
\hline \multirow[t]{2}{*}{11} & $\begin{array}{l}\text { A evolução das ciências caracteriza-se pela } \\
\text { autonomia no trabalho científico. Isto pressupõe a } \\
\text { independência do cientista em relação às } \\
\text { questões culturais, econômicas e sociais e } \\
\text { proporciona a busca sistemática de regularidades } \\
\text { observáveis. }\end{array}$ & 17 & 19 & 11 & 3 \\
\hline & $\begin{array}{l}\text { Responderam, concomitantemente, a ambas as } \\
\text { afirmativas }\end{array}$ & 1 & - & - & - \\
\hline
\end{tabular}

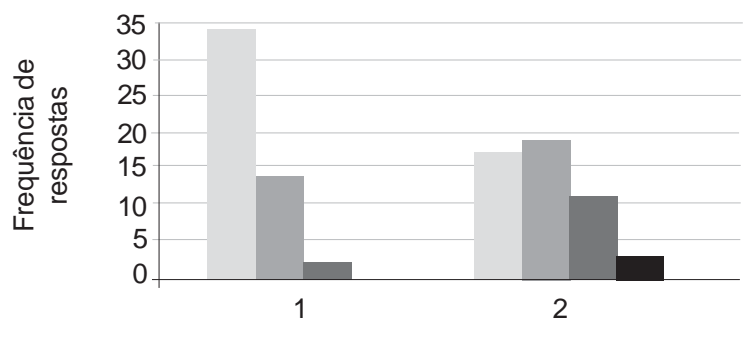

Concordo plenamente!

Concordo... parcialmente

Discordo

Estou indeciso(a)...

1. Paradigma emergente, pós-moderno

2. Paradigma clássimo, moderno

Gráfico 7. Ensinar as ciências em suas relações com a cultura x Ensinar as ciências da natureza, independentes de todo contexto.

Grande parte dos professores investigados, $68 \%$, concorda plenamente que é necessário haver controle ético e político da atividade científica, sendo que há ainda $28 \%$ que concordam em parte com esta afirmativa. Apenas 4\% dizem discordar deste princípio. 


\section{Chinelli, M. V.; Ferreira, M. V. S.; Aguiar, L. E. V.}

Já no que diz respeito à independência do cientista, que estaria desapegado das questões sociais para desenvolver seu trabalho científico, os informantes mostram-se muito divididos, até mesmo em dúvida (6\%). Entre estes professores, há 34\% que acreditam plenamente em uma ciência pura, desprovida de interesses e dissociada da cultura; $38 \%$, embora concordando, fazem alguma restrição a esta afirmativa; e $22 \%$ dizem discordar dela. Estes dados, assim como os anteriores, evidenciam a crise de paradigmas no ensino das ciências, implicando em incoerências que podem justificar dificuldades para o aprendizado, nas escolas.

$8^{a}$ oposição: Levar o aluno a compreender que as ciências são elaborações criativas, representações do real ligadas a um contexto e a uma finalidade x Ensinar ao aluno que há verdades sobre a natureza, as quais existem independentemente de qualquer ponto de vista e de qualquer objetivo (Tabela 8. Gráfico 8).

Tabela 8. Oposição entre conceber a ciência como modelagem do real, orientada por objetivos e concebê-la como verdade absoluta.

\begin{tabular}{|c|c|c|c|c|c|}
\hline & \multirow[b]{2}{*}{ Afirmativas } & \multicolumn{4}{|c|}{ Frequência } \\
\hline & & $\begin{array}{l}\text { Concordo } \\
\text { plenamente! }\end{array}$ & $\begin{array}{l}\text { Concordo... } \\
\text { parcialmente }\end{array}$ & Discordo & $\begin{array}{c}\text { Estou } \\
\text { indeciso (a) } \\
\end{array}$ \\
\hline 14 & $\begin{array}{l}\text { As ciências são elaborações criativas, } \\
\text { representações da realidade que correspondem } \\
\text { às interpretações dos cientistas. O } \\
\text { conhecimento é elaborado em função de } \\
\text { objetivos e tem ligações com o contexto em que } \\
\text { é produzido. }\end{array}$ & 33 & 12 & 2 & 3 \\
\hline \multirow[t]{2}{*}{5} & $\begin{array}{l}\text { Os cientistas são profissionais que trabalham } \\
\text { com abnegação para desvendar os mistérios da } \\
\text { natureza. É importante que os alunos possam } \\
\text { conhecer a verdade sobre o mundo natural, } \\
\text { descoberta pela ciência. }\end{array}$ & 29 & 20 & 1 & 0 \\
\hline & $\begin{array}{l}\text { Responderam, concomitantemente, a ambas as } \\
\text { afirmativas }\end{array}$ & 12 & - & - & - \\
\hline
\end{tabular}

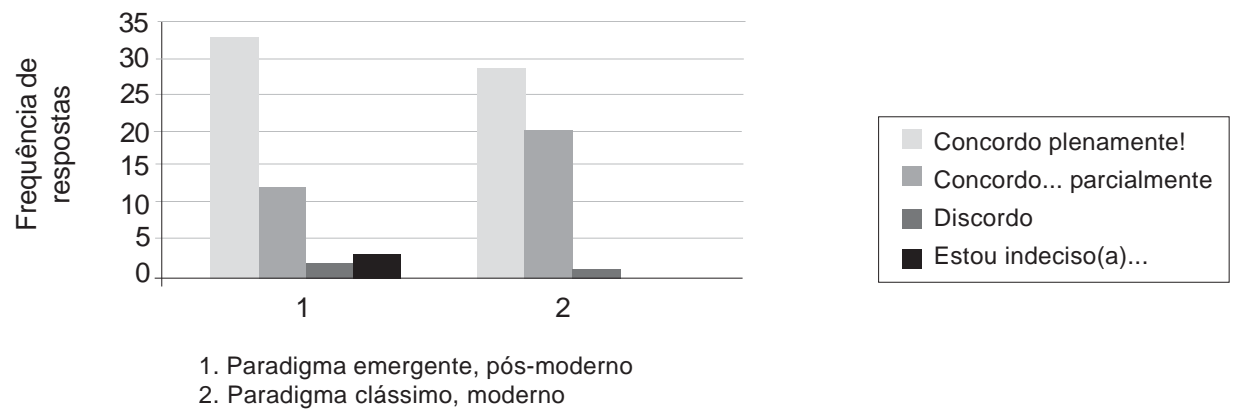

Gráfico 8. Ciência como representação da realidade x Ciência como verdade absoluta. 
Epistemologia em sala de aula: a natureza ...

Nestas afirmativas, um expressivo número de professores (24\%) concorda plenamente com ambas as afirmações, parecendo desconhecer que elas têm conteúdos bastante distintos. Este resultado traz preocupações, visto que, ao não encontrarem razões para discordar de qualquer das afirmações, estes professores demonstram que a abordagem que fazem dos conteúdos do ensino não considera as diferentes maneiras de pensar a ciência e os processos que levam à elaboração do conhecimento científico, o que pode resultar em um ensino mecânico, descontextualizado, desinteressante, sem sentido.

Os demais professores encontram-se muito divididos. A primeira afirmação diz respeito à concepção atual, que considera a ciência como uma atividade criativa, orientada por objetivos. Concordaram irrestritamente com esta afirmação, $66 \%$ dos professores pesquisados; $24 \%$ também concordam, em parte, sendo que $4 \%$ rejeitam esta afirmativa e $6 \%$ estão indecisos. A segunda afirmativa traz a concepção clássica da natureza da ciência - expressão da verdade sobre o mundo natural, que existe a priori, podendo ser descoberta com o trabalho dos cientistas. Praticamente todos os pesquisados concordam com essa concepção de ciência: 58\% concordam plenamente com a afirmação e $40 \%$ também concordam, mesmo que parcialmente.

\section{Conclusões}

Sobressai, nesta análise, a confirmação de que existem, convivendo nas escolas, duas concepções epistemológicas distintas, muitas vezes assumidas por um mesmo professor. Esta situação conflitante produz práticas pedagógicas antagônicas, fragilizando o ensino de ciências em razão de incoerências que podem ser sentidas pelos estudantes.

No entanto, há sinais de que os princípios que estruturam o novo paradigma despertem a atenção dos professores de ciências, uma vez que, em geral, não se opõem a ele. As respostas ao questionário apresentam os professores divididos, demonstrando alguma insegurança em assumirem o novo paradigma científico - baseado no pensamento hipotético-dedutivo e no caráter social da ciência -, mas, ao mesmo tempo, com muitas incertezas e algumas divergências em relação ao paradigma clássico, de caráter empiro-indutivista.

É um momento peculiar, em que os professores parecem inclinados a conhecer o novo. Um momento propício, portanto, para que tenham a oportunidade de: debater novas teorias, observar exemplos, viver experiências coerentes com propostas pedagógicas renovadas.

O processo didático pressupõe alguns elementos fundamentais que procuramos abordar nas questões propostas. Primeiro, pressupõe a mediação do professor na confrontação do aluno com o objeto do ensino: conhecimentos e atitudes que ele deverá aprender. Pressupõe, ainda, que o professor deve ter em mente os objetivos do ensino, e que irá levá-los em conta, na organização das situações de aprendizagem. Mas é preciso alertar que este não é um processo independente. A ação do professor, ao mesmo tempo em que expressa finalidades e exigências da prática social concreta, a ela se subordina, de modo que

Entender o processo didático como totalidade abrangente implica vincular conteúdos, ensino e aprendizagem a objetivos sócio-políticos e pedagógicos e analisar criteriosamente o conjunto das condições concretas que rodeiam cada situação didática. Em outras palavras, o ensi- 
no é um processo social, integrante de múltiplos processos sociais, no qual estão implicadas dimensões políticas, ideológicas, éticas, pedagógicas, frente às quais se formulam objetivos, conteúdos e métodos conforme opções assumidas pelo educador. (LIBÂNEO, 1993, p. 56)

O paradigma sociocientífico que vem se impondo coloca para a ciência questões como essas, tão presentes na educação, mas elas não têm sido plenamente reconhecidas pelos professores, como pudemos observar neste estudo.

A Didática das Ciências tem procurado se afirmar como um novo campo de conhecimentos, teoricamente fundamentado, e assim deixar de ser a parte instrumental ou metódica da pedagogia (CACHAPUZ et al., 2001). Para atingir status de ciência, este ramo da Didática apoia-se, em grande medida, na Psicologia Cognitiva, mas também na História e na Filosofia da Ciência. As bases do conceito construtivista defendido pelos pesquisadores do ensino de ciências dizem respeito a um modo de ensino que tenta aproximar a aprendizagem das características de uma investigação científica, dirigida pelo professor. Como dizem Cachapuz et al. (2005, p. 197), "as críticas feitas ao indutivismo por autores como Bachelard, Bunge, Feyerabend, Kuhn, Lakatos, Laudan, Popper, Toulmin etc., permitem compreender, do ponto de vista estritamente epistemológico, a relevância das primeiras concepções dos alunos quando confrontados com problemas científicos", um tema de muita importância nos estudos sobre o ensino e a aprendizagem.

Esta pesquisa reafirma, assim, a necessidade de se incluírem a epistemologia e a história das ciências nos currículos da formação inicial dos professores de ciências, e de se criarem oportunidades para que esses conhecimentos sejam abordados na formação continuada. No entanto, as inseguranças e desconhecimentos apresentados nas respostas aos questionários sugerem também a necessidade de que seja reforçada a formação sociológica dos professores, especialmente no que se refere às questões curriculares. De acordo com Moreira e Silva (1999, p. 20), as formulações da Sociologia do Currículo "têm constituído referência indispensável para todos os que se vêm esforçando por compreender as relações entre os processos de seleção, distribuição, organização e ensino dos conteúdos curriculares e a estrutura de poder do contexto social inclusivo". Estudos sobre o currículo são um aporte relevante para a definição dos objetivos do ensino, para a seleção dos conteúdos e para a organização das situações de aprendizagem, especialmente se o que se pretende é uma educação em ciência que considere as questões sociais e culturais envolvidas no desenvolvimento científico.

\section{Considerações finais}

As constatações deste trabalho nos levaram a defender, para os cursos de formação de professores, a inclusão de história e filosofia das ciências e de sociologia do currículo como componentes curriculares, visando minimizar incoerências observadas nas escolas. Mas não podemos deixar de assinalar que, a despeito da rejeição ao ensino tradicional, expressa em vários momentos, não é simples nem imediato modificar a epistemologia dos professores. Acreditamos, como Carvalho e Gil-Pérez (1995, p. 39-40), que os professores atuam impregnados de uma formação ambiental que adquiriram, sobretudo, quando alunos, as quais permane-

Ciência \&̊̃ Educação, v. 16, n. 1, p. 17-35, 2010 
Epistemologia em sala de aula: a natureza ...

cem orientando suas práticas pedagógicas "devido, de um lado, ao seu caráter reiterativo e, de outro, por sua natureza de exemplo vivo, real, muito mais eficaz que qualquer explicação, [o que] obriga a que as propostas de renovação [didática] sejam também vividas, vistas em ação".

Devemos, portanto, ultrapassar os muros da discussão teórica e levar os professores a observarem e a participarem de experiências que exemplifiquem aspectos desejáveis do planejamento e da organização do ensino ou que sejam oportunidades para a reflexão didática e pedagógica. Entre esses, podemos citar, com base nos resultados obtidos: experiências interdisciplinares; experimentos que estimulem a elaboração de hipóteses e permitam que sejam testadas; exemplos concretos das profundas relações existentes entre a ciência, a tecnologia, a sociedade e o ambiente; e oportunidades para que se discutam a democratização do conhecimento e questões éticas relacionadas à produção e à distribuição de produtos científicos e tecnológicos. Como também, a fim de contribuir para a ruptura com as barreiras paradigmáticas, experiências que envolvam a história da evolução dos conhecimentos científicos.

Os museus e centros de ciências parecem ser locais privilegiados para que essas experiências se deem. Com uma infraestrutura de que as escolas não dispõem - recursos materiais, equipes multidisciplinares, massa crítica para a preparação de atividades interessantes e significativas - e tempo disponível para o aproveitamento individualizado das experiências pelos visitantes, o que só a educação não formal permite, estes espaços poderão, se organizados neste sentido, contribuir para aproximar os professores do novo paradigma. Um paradigma que tem a marca da reflexão e da interdisciplinaridade, que reconhece o caráter social, cultural e histórico da construção do conhecimento.

\section{Referências}

CACHAPUZ, A. et al. (Orgs.). A necessária renovação do ensino das ciências. São Paulo: Cortez, 2005.

CACHAPUZ, A. et al. A emergência da didática das ciências como campo específico de conhecimento. Revista Portuguesa de Educação, Braga, v. 14, n. 1, p. 155-195, 2001. Disponível em: < http://redalyc.uaemex.mx/redalyc/pdf/374/37414108.pdf >. Acesso em: 27 abr. 2008.

CACHAPUZ, A.; PRAIA, J.; JORGE, M. Da educação em ciência às orientações para o ensino das ciências: um repensar epistemológico. Ciência \& Educação, Bauru, v. 10, n. 3, p. 363-381, 2004. Disponível em: <http://www2.fc.unesp.br/cienciaeeducacao/ viewarticle.php?id=31\&layout=abstract $>$. Acesso em: 30 jan. 2008.

CARVALHO, A. P. C.; GIL-PÉREZ, D. Formação de professores de ciências: tendências e inovações. 2. ed. São Paulo: Cortez, 1995.

CHINELLI, M. V. Tornar-se professor na experiência docente: saberes formados e mobilizados na prática profissional. 2001. 127f. Dissertação (Mestrado em Educação) Faculdade de Educação, Universidade do Estado do Rio de Janeiro, Rio de Janeiro, 2001. 
Chinelli, M. V.; Ferreira, M. V. S.; Aguiar, L. E. V.

CHINELLI, M. V.; AGUIAR, L. E. V. Subsídios para a formação permanente de professores de ciência e tecnologia: saberes formados e mobilizados na prática profissional. Rio de Janeiro: Instituto Oswaldo Cruz/Fiocruz, 2008a. (Inédito).

.; C C C C C c ensise no ensino de ciências: solicitações e desafios do paradigma emergente. Rio de Janeiro: Instituto Oswaldo Cruz/Fiocruz, 2008b. (Inédito).

FERNÁNDEZ, I. et al. Visiones deformadas de la ciência tansmitidas por la enseñanza. Enseñanza de las Ciencias, Barcelona, v. 20, n. 3, p. 477-488, 2002. Disponível em: $<$ http://www.raco.cat/index.php/Ensenanza/article/view/21841/21675>. Acesso em: 27 abr. 2008 .

FOUREZ, G. Crise no ensino de ciências? Investigação em Ensino de Ciências, Porto Alegre, v. 8, n. 2, p. 1-15, 2003. Disponível em: <http://www.if.ufrgs.br/public/ensino/ vol8/n2/v8_n2_a1.html>. Acesso em: 30 jan. 2008.

GALLEGO TORRES, A. P.; GALLEGO BADILLO, R. Historia, epistemología y didáctica de las ciencias: unas relaciones necesarias. Ciência \& Educação, Bauru, v. 13, n. 1, p. 85-98, 2007. Disponível em: < http://www.scielo.br/pdf/ciedu/v13n1/ v13n1a06.pdf>. Acesso em: 30 jan. 2008.

HARRES, J. B. S. Uma revisão de pesquisa nas concepções de professores sobre a natureza da ciência e suas implicações para o ensino. Investigações em Ensino de Ciências, Porto Alegre, v. 4, n. 3, p. 197-211, 1999. Disponível em: <http://www.if.ufrgs.br/public/ ensino/revista.htm>. Acesso em: 22 abr. 2008.

LIBÂNEO, J. C. Didática. São Paulo: Cortez, 1993.

MOREIRA, A. F. B.; SILVA, T. T. Sociologia e teoria crítica do currículo: uma introdução. In: ___ (Orgs.). Currículo, cultura e sociedade. 3. ed. São Paulo: Cortez, 1999. p. 7-37.

MOREIRA, M. A.; MASSONI, N. T.; OSTERMANN, F. "História e epistemologia da física" na licenciatura em física: uma disciplina que busca mudar concepções dos alunos sobre a natureza da ciência. Revista Brasileira de Ensino de Física, São Paulo, v. 29, n. 1, p. 127-134, 2007. Disponível em: <www.scielo.br/pdf/rbef/v29n1/a19v29n1.pdf>. Acesso em: 12 fev. 2008.

MORIN, E. Os sete saberes necessários à educação do futuro. 12. ed. São Paulo: Cortez, 2007.

Introdução ao pensamento complexo. Porto Alegre: Sulina, 2005.

. Ciência com consciência. 7. ed. Rio de Janeiro: Bertrand Brasil, 2003.

2002.

Educação e complexidade: os sete saberes e outros ensaios. São Paulo: Cortez,

NÓVOA, A. Formação de professores e profissão docente. In: . (Org.). Os professores e sua formação. 2. ed. Lisboa: Dom Quixote, 1992. p. 15-33. 
Epistemologia em sala de aula: a natureza ...

OCDE. Regards sur l'education: les indicateurs de l'OCDE edition 2002. Paris: Éditions OCDE, 2002.

PIAGET, J. La epistemología de las relaciones interdisciplinares. In: APOSTEL, L. et al. (Orgs.). Interdisciplinariedad: problemas de la enseñanza y de la investigación e las universidades. México: Asociación Nacional de Universidades e Institutos de Enseñanza Superior, 1979. p. 153-171.

PRAIA, J.; CACHAPUZ, A.; GIL-PÉREZ, D. Problema, teoria e observação em ciência: para uma reorientação epistemológica da Educação em Ciência. Ciência \& Educação, Bauru, v. 8, n. 1, p. 127-145, 2002. Disponível em: < http://vicenterisi.googlepages.com/ problemteoriaobservao.pdf>. Acesso em: 20 jan. 2008

PRAIA, J.; GIL-PÉREZ, D.; VILCHES, A. O papel da natureza da ciência na educação para a cidadania. Ciência \& Educação, Bauru, v. 13, n. 2, p. 141-156, 2007. Disponível em: <http://www.scielo.br/pdf/ciedu/v13n2/v13n2a01.pdf>. Acesso em: 30 jan. 2008.

PRIGOGINE, I.; STENGERS, I. A nova aliança: metamorfose da ciência. Brasília: Editora Universidade de Brasília, 1991.

RICHARDSON, R. J. Pesquisa social: métodos e técnicas. 3. ed. São Paulo: Atlas, 2007.

SANTOS, B. S. Um discurso sobre as ciências. 2. ed. São Paulo: Cortez, 2004a. 2004b. . (Org.). Conhecimento prudente para uma vida decente. São Paulo: Cortez,

TARDIF, M.; RAYMOND, D. Saberes, tempo e aprendizagem do trabalho no magistério. Educação e Sociedade, Campinas, v.21, n. 73, p. 209-244, 2000.

THERRIEN, J. O saber social da prática docente. Educação e Sociedade, Campinas, v.15, n. 46, p. 408-418, 1993. 